\title{
CORRIGENDUM
}

\section{The prebiotic concept and human health: a changing landscape with riboflavin as a novel prebiotic candidate?}

RE Steinert, M Sadaghian Sadabad, HJM Harmsen and P Weber

European Journal of Clinical Nutrition (2016) 70, 1461; doi:10.1038/ejcn.2016.141

Correction to: European Journal of Clinical Nutrition (2016) 70, The authors apologise for any inconvenience caused. 1348-1353; doi:10.1038/ejcn.2016.119; published online 6 July 2016

Since the publication of this article, the authors have noticed that the author name 'M Sadaghian Sadabad' was displayed incorrectly. The PDF and online versions have been amended. 